\title{
Interfacial Behavior of Pulmonary Surfactant Preparations Containing Egg Yolk Lecithin
}

\author{
Hiromichi Nakahara and Osamu Shibata* \\ Department of Biophysical Chemistry, Graduate School of Pharmaceutical Sciences, Nagasaki International University; 2825-7 Huis Ten Bosch, \\ Sasebo, Nagasaki 859-3298, Japan
}

\begin{abstract}
Mammalian lungs are covered with lipid-protein complexes or pulmonary surfactants. In this work, which aimed towards the less expensive production of artificial pulmonary surfactants, we produced surfactants composed of egg yolk lecithin (eggPC), palmitic acid, and hexadecanol $(=0.30 / 0.35 / 0.35, \mathrm{~mol} /$ $\mathrm{mol} / \mathrm{mol})$ containing different amounts of Hel 13-5 $\left(\mathrm{NH}_{2}-\right.$ KLLKLLLKLWLKLLKLLL-COOH) as a substitute for the proteins in native pulmonary surfactants. Surface pressure $(\pi)$-molecular area $(A)$ and surface potential $(\Delta V)-A$ isotherms of the mixtures were measured via the Wilhelmy and ionizing ${ }^{241}$ Am electrode methods, respectively. The interactions between the lipid components and Hel 13-5 led to variations in the surface pressure caused by the expulsion of fluid components from the surface. Furthermore, the $\pi-A$ and $\Delta V-A$ isotherms featured large hysteresis loops for the surfactant that contained a small amount of Hel 13-5 during compression and successive expansion cycling. To elucidate the morphology, the phase behavior was visualized in situ at the air-water interface by means of fluorescence microscopy; the images suggested less effective interactions between Hel 13-5 and the unsaturated PC in eggPC despite the similarity of their monolayer properties.
\end{abstract}

Key words: pulmonary surfactant, eggPC, palmitic acid, hexadecanol, surface pressure, surface potential

\section{INTRODUCTION}

Pulmonary surfactants, which play an essential role in pulmonary function by reducing the surface tension of the alveoli ${ }^{1)}$, are lipid-protein complexes that are composed mainly of phospholipids such as dipalmitoylphosphatidylcholine (DPPC) and phosphatidylglycerol $(\mathrm{PG})^{2-4)}$. Surfactant-associated proteins (i.e., SP-A, SP-B, SP-C, and SP-D) are present in pulmonary surfactants in relatively small amounts but are quite important for control of the lipid components at the surface ${ }^{5)}$. Among them, SP-B and SP-C have a significant effect on the surface activity ${ }^{2}$. The functions of pulmonary surfactants have been summarized well in review articles ${ }^{1,5-8)}$. An artificial pulmonary surfactant, i.e. Surfacten ${ }^{\circledR}$, which is a bovine pulmonary surfactant extract supplemented with DPPC, palmitic acid (PA), and tripalmitin, has been used in Japan as a first-line medicine for neonatal respiratory distress syndrome(NRDS), which is caused by a native lack of pulmonary surfactants. Although it is considerably effective for treatment of NRDS patients, Surfacten ${ }^{\circledR}$ is assumed to involve the risk of anthropozoonosis. In this regard, alternative lung-extract medicines that do not contain animal-derived compounds have been extensively developed ${ }^{9-13)}$. Aside from the efficacy, such compounds are less expensive to prepare and have fewer side effects. Synthetic surfactants are classified into two categories: protein (or peptide)-free surfactants (e.g., Exosurf $\left.{ }^{\circledR}\right)^{14-16)}$ and protein (peptide)-containing surfactants (e.g., Surfaxin $\left.{ }^{\circledR}\right)^{9-11)}$. Indeed, the surfactants that contain peptides have shown positive results of improved effectiveness for NRDS. DPPC, PG, PA, and hexadecanol (HD) are often contained in these surfactants ${ }^{10,16-18)}$. Among them, DPPC is, in particular, utilized to a large extent as a lipid substitute for pulmonary surfactants. The use of DPPC, however, is expensive, which prevents its application to other pulmonary diseases. In fact, the cost of Surfaxin $^{\circledR}$, which is the first FDA-approved synthetic, peptide-containing surfactant, is not considerably different from that of Surfacten ${ }^{\circledR 19)}$.

We reported that pulmonary surfactants containing amphiphilic basic peptides (i.e., Hel 13-5) feature pulmonary activities and functions ${ }^{20-22)}$. The Hel $13-5$ peptide has been extensively characterized via many techniques including CD spectroscopy, electron microscopy, IR spectroscopy, etc ${ }^{23-27)}$. From these results, this peptide was deter-

\footnotetext{
*Correspondence to: Osamu Shibata, Department of Biophysical Chemistry, Graduate School of Pharmaceutical Sciences, Nagasaki International University; 2825-7 Huis Ten Bosch, Sasebo, Nagasaki 859-3298, Japan

E-mail: wosamu@ niu.ac.jp

Accepted July 26, 2014 (received for review May 27, 2014)

Journal of Oleo Science ISSN 1345-8957 print / ISSN 1347-3352 online

http://www.jstage.jst.go.jp/browse/jos/ http://mc.manusriptcentral.com/jjocs
} 


\section{H. Nakahara and O. Shibata}

mined to be a membrane-surface staying-type peptide, which is the same as SP-B. Recently, it was reported that a hydrogenated soy lecithin/soy lecithin/PA/Hel 13-5 mixture exhibited surfactant activity comparable to that of Surfac$\operatorname{ten}^{(27,28)}$; this suggests that artificial surfactants that do not contain synthetic DPPC and PG are possible. In a previous study ${ }^{19)}$, we considered egg yolk phosphatidylcholine (eggPC) extracted and purified from relatively inexpensive egg yolk as an alternative to DPPC. The fatty-acid moieties in eggPC comprised double hydrocarbon chains composed of both saturated and unsaturated acyl chains: DPPC (2C16:0) was a large component. As a result, the eggPC/ $\mathrm{PA} / \mathrm{HD}(=0.30 / 0.35 / 0.35, \mathrm{~mol} / \mathrm{mol} / \mathrm{mol})$ mixture showed the surface behavior required for pulmonary functions.

In the present study, the interfacial behaviors of eggPC/ $\mathrm{PA} / \mathrm{HD}(=0.30 / 0.35 / 0.35, \mathrm{~mol} / \mathrm{mol} / \mathrm{mol})$ mixtures containing different amounts of Hel 13-5 were examined via the Langmuir monolayer technique. Surface pressure $(\pi)$-molecular area $(A)$ and surface potential $(\Delta V)-A$ isotherms of the mixtures were measured on $0.02 \mathrm{M}$ Tris buffer with $0.13 \mathrm{M}$ $\mathrm{NaCl}(\mathrm{pH} 7.4)$ at $298.2 \mathrm{~K}$. The phase change and morphology of the monolayer upon compression were visualized using in situ fluorescence microscopy (FM). Furthermore, repeated compression-expansion curves of the $\pi-A$ and $\Delta V-A$ isotherms were examined to evaluate the pulmonary functions of the surfactants, such as expulsion activity and re-spreading capacity of the peptide in the interfacial region.

\section{EXPERIMENTAL}

\subsection{Materials}

Egg yolk lecithin PC-98N (>98\% phosphatidylcholine; virus-free; lot\# AT2002) was provided as a gift from the Kewpie Corporation Fine Chemical Division(Tokyo, Japan). $n$-Hexadecanoic acid (also known as palmitic acid (PA); 99\%) was purchased from Sigma-Aldrich Co. (St. Louis, MO) . 1-Hexadecanol (palmityl alcohol (HD); >99\%) was obtained from nacalai tesque (Kyoto, Japan). 3,6-Bis (diethylamino)-9-(2-octadecyloxycarbonyl) phenyl chloride (R18) from Molecular Probes, Inc. (Eugene, OR) was employed as a fluorescent probe. These lipids were used without further purification. The Hel $13-5\left(\mathrm{NH}_{2}-\right.$ KLLKLLLKLWLKLLKLLL-COOH) peptide was synthesized using the 9-fluorenylmethoxycarbonyl (Fmoc) technique and purified using reverse-phase HPLC, as described in the literature $^{23)}$. More detailed procedures for the synthesis, purification, and analysis of Hel 13-5 were reported previously $^{24,25)} \cdot n$-Hexane (98.5\%) and ethanol (99.5\%) were purchased from Merck (Uvasol ${ }^{\circledR}$, Darmstadt, Germany) and nacalai tesque, respectively; $n$-hexane/ethanol $(9 / 1 \mathrm{v} / \mathrm{v}$ for the lipids and 4.5/5.5 v/v for Hel 13-5) mixtures were used as spreading solvents. Tris (hydroxymethyl) aminomethane
(Tris) and reagent-grade acetic acid (HAc) for the preparation of the subphase were obtained from nacalai tesque. Sodium chloride (nacalai tesque) was roasted at $1023 \mathrm{~K}$ for $24 \mathrm{~h}$ to remove all surface-active organic impurities. The substrate solution was prepared using thrice-distilled water (surface tension: $72.0 \mathrm{mN} \mathrm{m}^{-1}$ at $298.2 \mathrm{~K}$; electrical resistivity: $18 \mathrm{M} \Omega \mathrm{cm})$. The $\mathrm{pH}$ of the subphase $(0.02 \mathrm{M}$ Tris buffer and $0.13 \mathrm{M} \mathrm{NaCl}$ ) was adjusted to 7.4 using HAc.

\subsection{Methods}

\subsubsection{Surface pressure-area isotherms}

The $\pi$ values of the monolayers were measured using an automated homemade Wilhelmy balance. The surfacepressure balance (Mettler Toledo, AG-64) had a resolution of $0.01 \mathrm{mN} \mathrm{m}^{-1}$. The pressure-measuring system was equipped with filter paper (Whatman 541, periphery: 4 $\mathrm{cm})$. The trough was made from Teflon ${ }^{\circledR}$-coated brass (area: $750 \mathrm{~cm}^{2}$ ), and Teflon ${ }^{\circledR}$ barriers (both hydrophobic and lipophobic) were used in this study. Surface pressure $(\pi)$-molecular area $(A)$ isotherms were recorded at $298.2 \pm$ $0.1 \mathrm{~K} . n$-Hexane/ethanol stock solutions of eggPC (1.3 $\mathrm{mM}), \mathrm{PA}(1.3 \mathrm{mM}), \mathrm{HD}(1.3 \mathrm{mM})$, and Hel 13-5 (0.13 mM) were prepared. The spreading solvents were allowed to evaporate for $15 \mathrm{~min}$ prior to compression. The monolayer was compressed at a speed of $\sim 0.10 \mathrm{~nm}^{2}$ molecule ${ }^{-1} \mathrm{~min}^{-1}$, which provided almost equilibrium $\pi$ values at each molecular area ${ }^{13,29)}$. The standard deviations (SD) for $A$ and $\pi$ were $\sim 0.01 \mathrm{~nm}^{2}$ and $\sim 0.1 \mathrm{mN} \mathrm{m}^{-1}$, respectively ${ }^{20,30,31)}$.

\subsubsection{Surface potential-area isotherms}

The surface potentials were recorded simultaneously with surface pressure as the monolayers were compressed and expanded at the air-water interface; they were monitored with an ionizing ${ }^{241} \mathrm{Am}$ electrode $1-2 \mathrm{~mm}$ above the interface while a reference electrode was dipped in the subphase. An electrometer (Keithley 614) was used to measure the surface potential. The SD for $\Delta V$ was $5 \mathrm{mV}^{32,33)}$. 2.2.3 Fluorescence microscopy (FM)

Fluorescence-microscope (U.S.I. System BM-1000) observations and compression-isotherm measurements were carried out simultaneously. A spreading solution of the surfactants was prepared as a mixed solution doped with 1 mol\% fluorescence probe(R18). A $300 \mathrm{~W}$ xenon lamp(XL 300, Pneum) was used to excite the FM probes. The excitation and emission wavelengths were selected using an appropriate beam splitter/filter combination (Mitutoyo band path filter: $546 \mathrm{~nm}$; Olympus cut filter: $590 \mathrm{~nm}$ ). The monolayer was observed using a 20 -fold magnification longdistance objective lens (Mitutoyo, $f: 200$; focal length: 20 $\mathrm{mm})$. Fluorescent micrographs were recorded with a video camera (757 JAI ICCD camera, Copenhagen, Denmark) connected to the microscope directly into computer memory via an on-line image processor (VAIO PCV-R53 Sony, Video Capture Soft). The entire optical setup was placed on an active vibration-isolation unit (model-AY-1812, 
Visolator, Meiritz Seiki Co. Ltd., Yokohama, Japan) ${ }^{29,34)}$.

\section{RESULTS AND DISCUSSION}

\section{$3.1 \pi-A$ and $\Delta V-A$ isotherms}

The $\pi-A$ and $\Delta V-A$ isotherms for the eggPC/PA/HD ( $=0.30 / 0.35 / 0.35 \mathrm{~mol} / \mathrm{mol} / \mathrm{mol})$ monolayers containing different amounts of Hel 13-5 on 0.02 M Tris buffer solution with $0.13 \mathrm{M} \mathrm{NaCl}(\mathrm{pH} 7.4)$ at $298.2 \mathrm{~K}$ are shown in Fig. 1. Note that eggPC contained $\sim 45 \%$ saturated aliphatic chains in fatty acid moieties ${ }^{19)}$. Hel 13-5 (curve 5) formed a typical disordered monolayer with a collapse pressure $\left(\pi^{\mathrm{c}}\right)$ of $\sim 42 \mathrm{mN} \mathrm{m}^{-112,20,21)}$. Incorporation of Hel 13-5 into the eggPC/PA/HD mixture resulted in a shift in the $\pi-A$ isotherms that depended on the mole fraction of Hel 13-5 ( $\left.X_{\text {Hel 13-5 }}\right)$. However, the shapes of the $\pi-A$ isotherms for $X_{\text {Hel 13-5 }} \leq 0.1$ were significantly affected by the addition of Hel 13-5. The $\Delta V-A$ isotherms of the Hel 13-5 monolayers showed a monotonous increase in $\Delta V$ as the molecular areas reduced to $\sim 2.0 \mathrm{~nm}^{2}$, which is characteristic of disordered monolayers. After the collapse, the $\Delta V$ value remained constant upon further compression. As for $X_{\mathrm{Hel} \mathrm{13-5}}=0.4$ (curve 3), an abrupt and less sharp increase in $\Delta V$ appeared at $\sim 3.5$

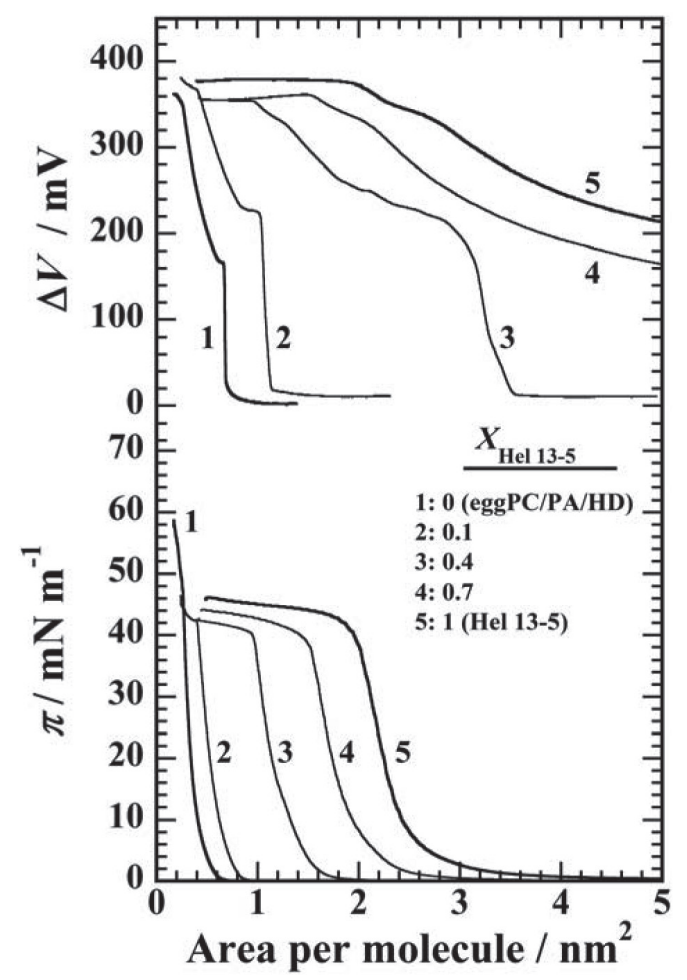

Fig 1 The $\pi-A$ and $\Delta V-A$ isotherms of the eggPC/PA/ $\mathrm{HD}(=0.30 / 0.35 / 0.35, \mathrm{~mol} / \mathrm{mol} / \mathrm{mol})$ monolayers containing Hel 13-5 for $X_{\text {Hel 13-5 }}=0,0.1,0.4,0.7$, and 1 on $0.02 \mathrm{M}$ Tris buffer solution with $0.13 \mathrm{M}$ $\mathrm{NaCl}(\mathrm{pH} 7.4)$ at $298.2 \mathrm{~K}$. $\mathrm{nm}^{2}$, which reflected a phase transition from a dilute to disordered state; this type of increase was also observed for mixtures with $X_{\text {Hel 13-5 }}=0.7$ (curve 4) and Hel 13-5 at $A>5.0$ $\mathrm{nm}^{2}$ (data not shown). Consequently, it was found that the addition of a relatively large amount of Hel 13-5 $\left(X_{\mathrm{Hel} \mathrm{13-5}}>\right.$ 0.1 ) masked the surface properties of the lipid mixture. Therefore, we focused on surfactants in which $X_{\text {Hel 13-5 }}<0.1$.

Figure 2 shows the $\pi-A$ and $\Delta V-A$ isotherms for mixtures with $X_{\text {Hel 13-5 }} \leq 0.1$. The eggPC/PA/HD $(=0.30 / 0.35 /$ $0.35, \mathrm{~mol} / \mathrm{mol} / \mathrm{mol}$ ) mixture formed a typical immiscible monolayer between the liquid-expanded (LE) and liquidcondensed phases $(\mathrm{LC})^{19)}$ : There were two kinks that corresponded to the collapse pressures of eggPC and the $\mathrm{PA} /$ HD monolayers on the isotherm. The $\pi-A$ isotherm (curve 1) exhibited a kink at $\sim 47 \mathrm{mN} \mathrm{m}^{-1}$; the kink point corresponded to monolayer collapse of the unsaturated components in eggPC. Then, at $\sim 54 \mathrm{mN} \mathrm{m}^{-1}$, the isotherm collapsed for the mixed monolayer composed of PA, HD, and the saturated components in eggPC. When Hel 13-5 was added to the lipid monolayer, the $\pi-A$ isotherm moved to larger $A$ values below $\sim 42 \mathrm{mN} \mathrm{m}^{-1}$. In contrast, above $\sim$ $42 \mathrm{mN} \mathrm{m}^{-1}$, the isotherm shifted to smaller $A$ values and finally plateaued at $\sim 0.13 \mathrm{~nm}^{2}$; this was induced by the expulsion of Hel 13-5 from the surface at $\sim 42 \mathrm{mN} \mathrm{m}^{-122,26,35)}$.

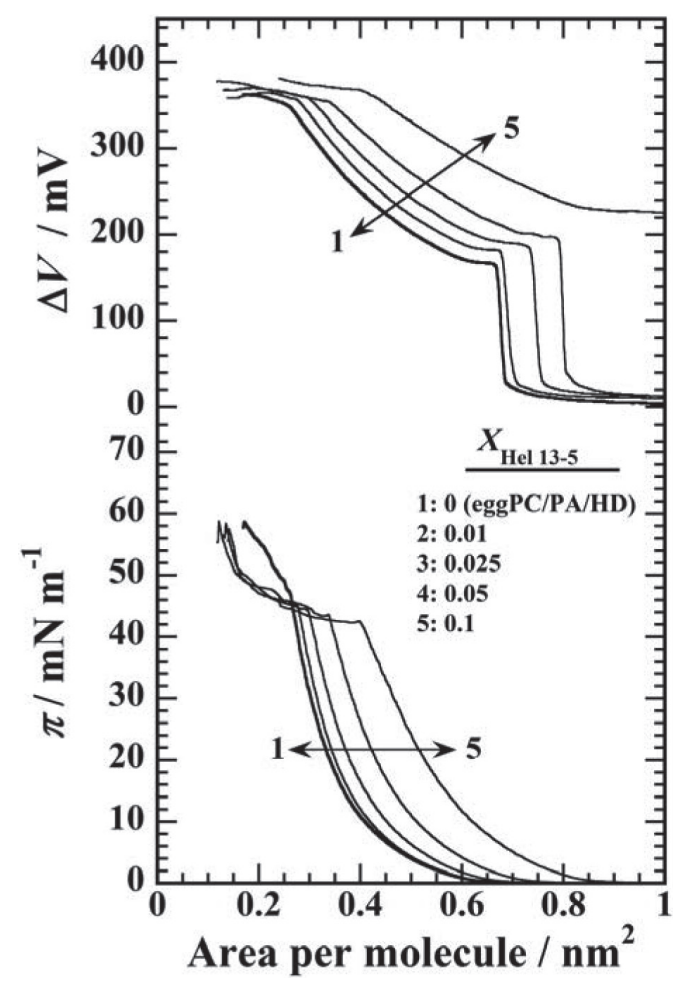

Fig 2 The $\pi-A$ and $\Delta V-A$ isotherms of the eggPC/PA/ $\mathrm{HD}(=0.30 / 0.35 / 0.35, \mathrm{~mol} / \mathrm{mol} / \mathrm{mol})$ monolayers containing small amounts of Hel 13-5 (0 $\leq X_{\text {Hel 13-5 }}$ $\leq 0.1)$ on $0.02 \mathrm{M}$ Tris buffer solution with 0.13 $\mathrm{M} \mathrm{NaCl}(\mathrm{pH} 7.4)$ at $298.2 \mathrm{~K}$. 


\section{H. Nakahara and O. Shibata}

(A)

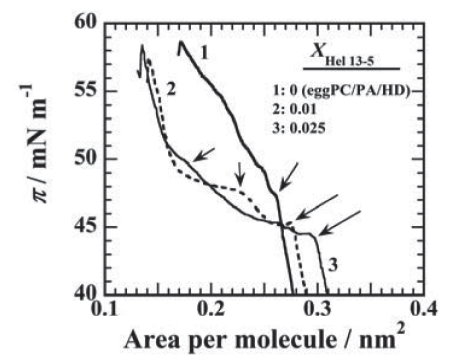

(B)

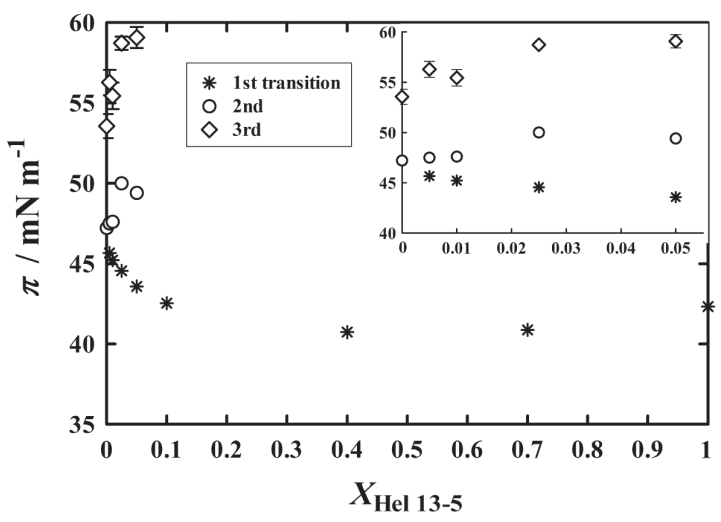

Fig 3 (A) The expanded $\pi-A$ isotherms of the eggPC/ $\mathrm{PA} / \mathrm{HD} / \mathrm{Hel} \mathrm{13-5}$ system for $X_{\text {Hel 13-5 }}=0,0.01$, and 0.025 . (B) Change in the $\pi$ value corresponding to kink points on $\pi-A$ isotherms with respect to $X_{\text {Hel 13-5. }}$ (Inset in Fig. 3B) Enlarged plots in the $X_{\text {Hel 13-5 }}$ region of 0 to 0.05 .

This phenomenon has been well-discussed elsewhere ${ }^{36,37)}$. After almost complete exclusion, the $\pi$ value began to in- crease again upon compression. The $\Delta V-A$ isotherms showed a $\Delta V$ jump, which was sharper than that for $X_{\text {Hel 13-5 }}$ $=0.4($ Fig. 1 , curve 3). These $\Delta V$ jumps reflected the phase transition of the eggPC/PA/HD monolayer from a gaseous to LE state. The $\Delta V-A$ isotherms shifted to larger $A$ values as $X_{\mathrm{Hel} \mathrm{13-5}}$ increased. The maximum $\Delta V$ values increased slightly compared to that of the eggPC/PA/HD mixture (curve 1); this implied that the Hel 13-5 molecules were not completely expelled from the surface even when close-packed $^{21)}$.

The $\pi-A$ isotherms had several kinks corresponding to the phase transitions above $\sim 42 \mathrm{mN} \mathrm{m}^{-1}$. In Fig. 3A, the definite kinks are indicated by arrows. Except for the eggPC/PA/HD monolayer (curve 1 ), the $\pi-A$ isotherms exhibited the first kink upon compression beyond their respective onset $A$ values; these kinks were generated by the expulsion of Hel 13-5 (represented by the dashed arrows in Scheme 1). Upon further compression, a second kink appeared on the isotherm for mixtures with $X_{\mathrm{Hel} \mathrm{13-5}} \leq 0.05$. As mentioned above, the second kink represented collapse of the unsaturated components in eggPC (represented by the solid arrow in Scheme 1). It was evident that the first and second kinks emerged independently on the isotherms, i.e., we propose that Hel 13-5 was immiscible even with unsaturated PC despite the similarities of their monolayer phase properties. Finally, the monolayer collapsed completely at $\pi^{\mathrm{c}}\left(\sim 57 \mathrm{mN} \mathrm{m}^{-1}\right.$, third transition). Figure 3B shows plots of the surface pressure at the kinks as a function of $X_{\mathrm{Hel} \mathrm{13-5}}$. The $\pi$ value at the first kink remained almost constant when $X_{\text {Hel 13-5 }} \geq 0.1$. In contrast, when $0<X_{\text {Hel 13-5 }} \leq 0.1$, the $\pi$ value increased with decreasing $X_{\text {Hel 13-5; }}$, this indicated the favorable interaction of Hel 13-5 with certain components in eggPC/PA/HD. In a previous report ${ }^{38)}$, it was suggested that the dissociated PA, which was negatively charged, interacted with Hel 13-5, which was positively charged, by

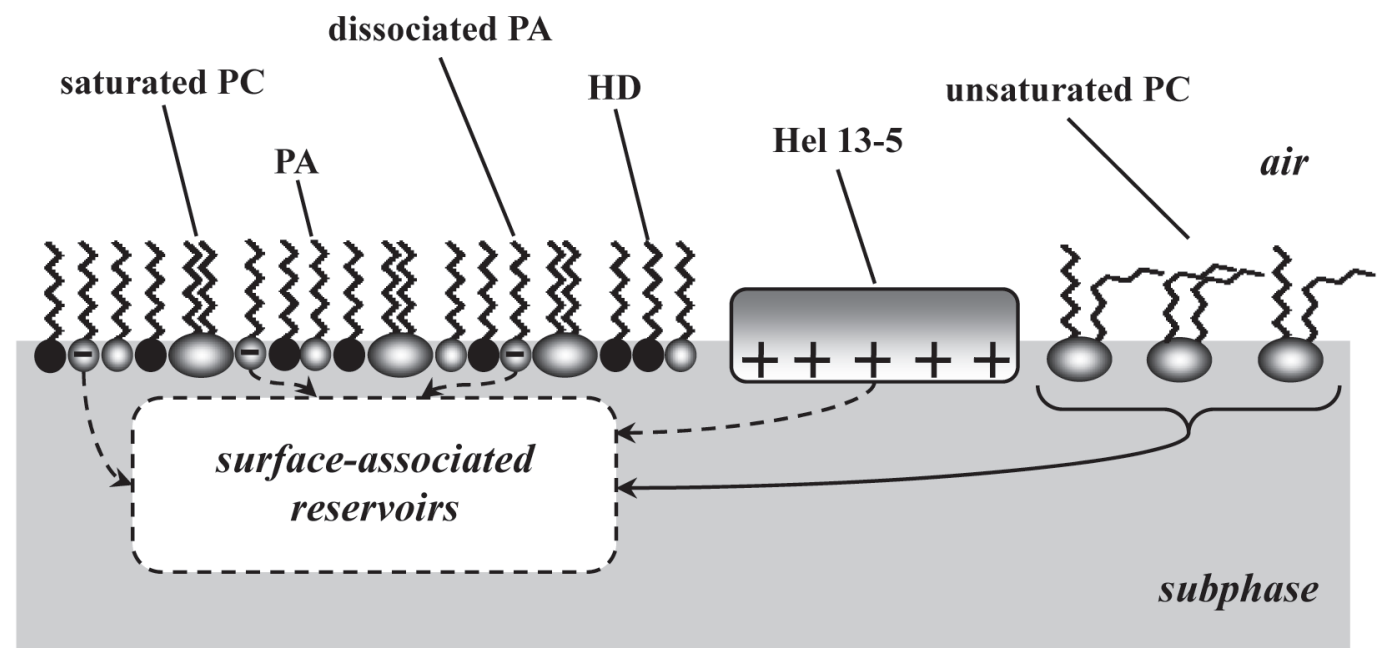

Scheme 1 Possible explanation for the stepwise elimination of the respective components in the pulmonary surfactant preparations upon compression. 
means of electrostatic attraction. Because Hel 13-5 was much bulkier than the lipid here, the interactions of Hel 13-5 were dominated by strong electrostatic attractions rather than weak van der Waals attractions. In contrast, the $\pi$ value at the second kink remained constant when $0 \leq X_{\text {Hel 13-5 }}$ $\leq 0.01$ (inset in Fig. 3B). However, the $\pi$ value increased slightly when $X_{\text {Hel } 13-5}=0.025$ and 0.05 , which meant that the unsaturated PC was difficult to expel from the surface. It is commonly accepted in the research field of pulmonary surfactants that the excluded peptides or proteins form a surface-associated reservoir below the interface to stabilize the monolayer ${ }^{39-42)}$. Thus, the present behavior was attributed to the formation of reservoirs composed of Hel 13-5 and dissociated $\mathrm{PA}^{38)}$. Nevertheless, this result supported the fact that Hel 13-5 had fewer interactions with unsaturated PC. As for the third transition, the $\pi$ value increased with increasing $X_{\text {Hel 13-5; }}$ this was primarily caused by the formation of a surface-associated reservoir, which is quite important for improvement of monolayer stability for pulmonary surfactants.

\subsection{In situ FM observations}

Figure 4 shows FM images of the eggPC/PA/HD ( = $0.30 / 0.35 / 0.35, \mathrm{~mol} / \mathrm{mol} / \mathrm{mol}$ ) monolayers that contain different amounts of Hel 13-5 at the air-water interface. In the FM observation, the monolayer contained a small
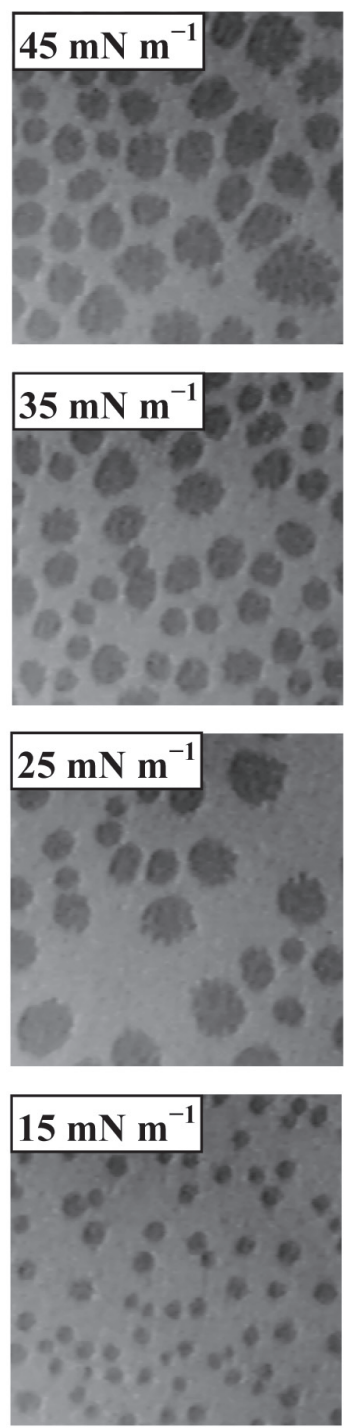

$\operatorname{eggPC/PA} / H D$
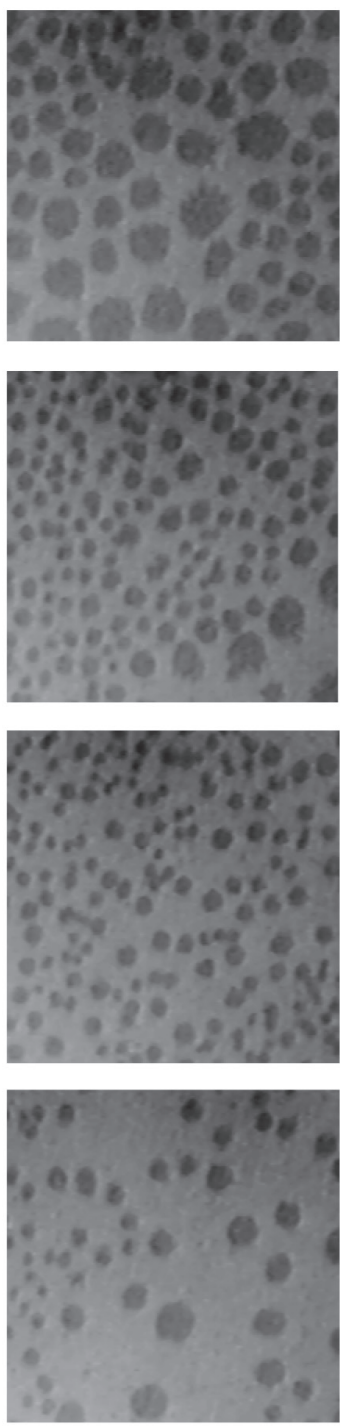

$X_{\text {Hel 13-5 }}=0.01$
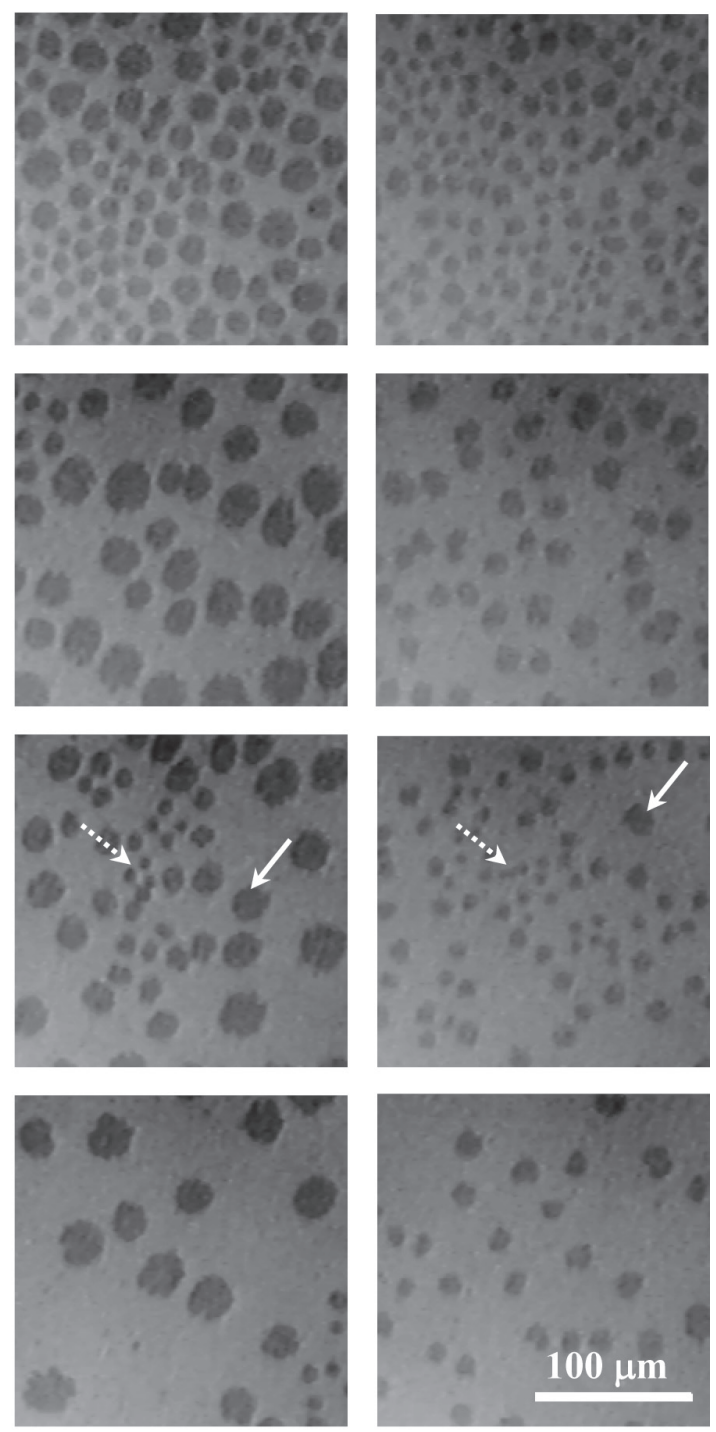

$X_{\text {Hel 13-5 }}=0.025$

Fig 4 FM images of the eggPC/PA/HD/Hel 13-5 monolayers for $X_{\mathrm{Hel} 13-5}=0,0.01,0.025$, and 0.05 at 15, 25, 35, and 45 $\mathrm{mN} \mathrm{m}^{-1}$ on $0.02 \mathrm{M}$ Tris buffer solution with $0.13 \mathrm{M} \mathrm{NaCl}(\mathrm{pH} 7.4)$ at $298.2 \mathrm{~K}$. The monolayers contained 1 mol\% Fluorescent probe (R18). The scale bar in the lower right represents $100 \mu \mathrm{m}$. 


\section{H. Nakahara and O. Shibata}

amount of a fluorescent probe(1 mol\% R18). Generally, the fluorescent probe selectively dissolves in disordered phases of monolayers because of its bulky conjugate moieties. Thus, the bright and dark contrasts in the FM image corresponded to LE and LC phases, respectively. As for the eggPC/PA/HD monolayer, homogeneous dark images (the gaseous phase) continued above $A=0.69 \mathrm{~nm}^{2}$, which was the onset area of the $\Delta V$ jump (Fig. 2, curve 1). Further compression changed the images to feature coexistent LE (bright) and LC (dark) phases. With increasing surface pressure from $15 \mathrm{mN} \mathrm{m}^{-1}$, the LC domains increased in size but the coexistence state continued until the monolayer collapsed; this provided evidence that the eggPC/PA/HD mixture formed immiscible (or phase-separated) monolayers, i.e., the saturated PC was miscible with the PA/HD mixture but the resultant mixture was less miscible with the unsaturated PC. The monolayer miscibility of saturated PCs, such as DPPC, and PA or HD has been well-discussed in previous reports ${ }^{43-46)}$. The FM images of the Hel 13-5 monolayers were expressed as a bright contrast over the entire range of surface pressures ${ }^{21 \text { ) }}$.

By incorporating Hel 13-5 into the lipid mixture, we elucidated the effect of Hel 13-5 on the morphology of the lipid monolayer. Monolayers of mixtures with $0.01 \leq X_{\text {Hel 13-5 }}$ $\leq 0.05$ showed similar morphology as that without Hel 13-5, regardless of surface pressure. In a strict sense, the uneven LC domains were generated by addition of Hel 13-5: The large domains (indicated by the solid arrows) with diameters of $\sim 15-30 \mu \mathrm{m}$ and the small domains (indicated by dashed arrows) with diameters of $\sim 5-12 \mu \mathrm{m}$ coexisted in the FM images. Considering that the small domains remained round, this heterogeneous behavior was interpreted as the contribution of Hel 13-5 to negative line tension at the boundary between the LE and LC domains ${ }^{47-50)}$. However, the influence of Hel 13-5 on the LC domains was relatively small compared to in other systems ${ }^{12,22,38)}$. Assuming that Hel 13-5 was well-miscible with the unsaturated PC, the morphologies were expected to produce LC domains with uniform sizes (or diameters). In this regard, these FM images supported the less favorable interactions between Hel 13-5 and the unsaturated PC.

\subsection{Hysteresis behavior of the isotherms}

Beyond the $\pi$ value of the expulsion of Hel 13-5, lateral compression of the monolayers induced ejection of the fluid components, such as the unsaturated PC and Hel 13-5, from the air-water interface to form the surface-associated reservoir, which contributed to prevention of the alveolar collapse. Upon successive expansion, the expelled molecules reentered with a delay and then spread back into the surface. This process is commonly called respreading. The delay produced a large hysteresis loop on the $\pi-A$ isotherms. Both the large hysteresis loop and its reproducibility were very important to elucidating the pul- monary function and activity ${ }^{51)}$. In the present study, the monolayer was compressed up to the appropriate $\pi^{\mathrm{c}}$ value and then expanded to the initial molecular areas. This process was successively repeated to examine the reproducibility of the respreading process within a monolayer. Figure 5 shows the compression-expansion curves regarding the $\pi-A$ and $\Delta V-A$ isotherms from the first to fifth cycles. Both isotherms of the eggPC/PA/HD monolayers exhibited hysteresis loops (Fig. 5A). However, the reproducibility during cycling was not very good: The isotherms shifted to smaller $A$ values with increasing cycling number. This shift was considered to result from the irreversible exclusion of the unsaturated PC and/or the lack of respreading capacity onto the surface; both factors were generated from the absence of peptides or proteins in the surfactants $^{5)}$. In mixtures with $X_{\text {Hel 13-5 }}=0.01$ (Fig. 5B), the $\pi-A$ and $\Delta V-A$ isotherms were better concentrated than those of the eggPC/PA/HD monolayer. However, the hysteresis loop became smaller in the enclosed square during cycling. In particular, the $\Delta V-A$ isotherms were identical in the compression and successive expansion stages. That is, the respreading properties were improved by the addition of Hel $13-5\left(X_{\text {Hel 13-5 }}=0.01\right)$; however, the delay in the surface activity and molecular orientation at the interface did not occur completely. When $X_{\text {Hel 13-5 }}=0.025$ (Fig. 5C), the hysteresis loops on both isotherms were significantly enhanced in the enclosed areas and reproducibility. The hysteresis loops on the $\Delta V-A$ isotherms were caused by electrostatic interactions between the dissociated PA and Hel $13-5^{22,26,35,38)}$. Variation of the amount of Hel 13-5 in the mixtures revealed that $2.5 \mathrm{~mol} \% \mathrm{Hel} 13-5$ was required to produce reproducible hysteresis properties. In previous studies ${ }^{12,20-22)}$, pulmonary surfactants, such as DPPC/Hel 13-5, dipalmitoylphosphatidylglycerol (DPPG)/Hel 13-5, DPPC/DPPG/ Hel 13-5, and DPPC/PG/PA/Hel 13-5, had similar efficacies as those containing $\sim 5.0-10 \mathrm{~mol} \%$ Hel $13-5$. In a previous study ${ }^{12)}$, we reported the temperature dependence of the pulmonary surfactant (DPPC/PG/PA/Hel 13-5) and Surfacten $^{\circledR}$ in the monolayer state. The $\pi$ value, which represented the expulsion of Hel 13-5 and the proteins, remained almost constant upon increasing the temperature to 310.2 $\mathrm{K}$. In the present study, although the temperature-dependent behavior was not examined, it was evident that the unsaturated PC in eggPC significantly promoted the Hel 13-5 activity related to pulmonary functions.

\section{CONCLUSION}

Pulmonary surfactant lipids composed of PA and HD as well as eggPC, which consists of saturated and unsaturated $\mathrm{PC}$, were investigated using the Langmuir monolayer technique. The eggPC/PA/HD $(=0.30 / 0.35 / 0.35$, by $\mathrm{mol} / \mathrm{mol} /$ $\mathrm{mol}$ ) mixture formed a phase-separated monolayer at the 

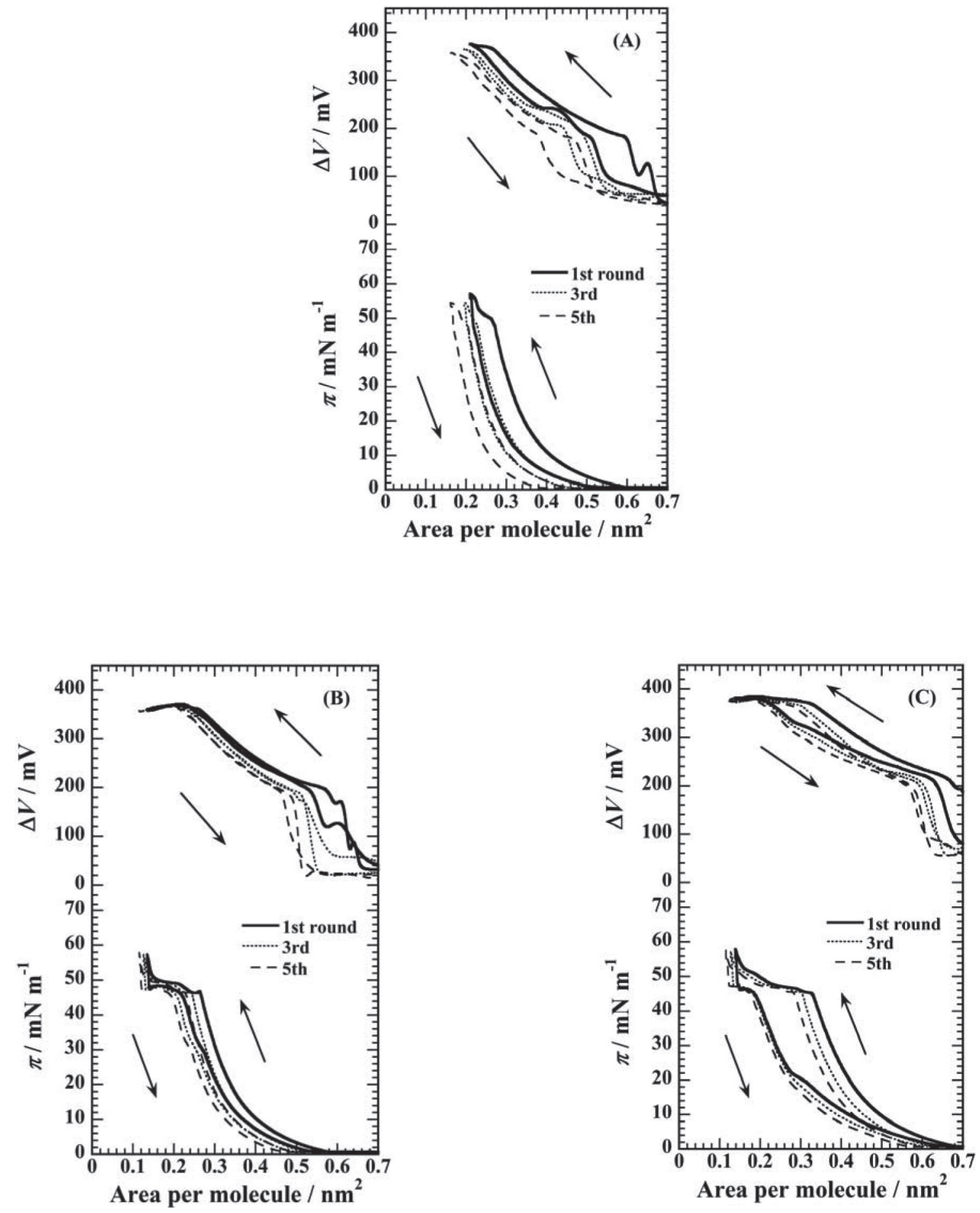

Fig 5 Cyclic compression and expansion isotherms of the eggPC/PA/HD/Hel 13-5 monolayers for $X_{\text {Hel } 13-5}=0(\mathrm{~A}), 0.01$ (B), and $0.025(\mathrm{C})$ on $0.02 \mathrm{M}$ Tris buffer solution (pH 7.4) with $0.13 \mathrm{M} \mathrm{NaCl}$ at $298.2 \mathrm{~K}$. The compression-expansion cycle was performed five times.

air-water interface. The expulsion of Hel 13-5 from the surface lipid monolayers was confirmed by the $\pi-A$ isotherms in the small $X_{\mathrm{Hel} \mathrm{13-5}}$ regions. FM images of the eggPC/PA/HD/Hel 13-5 system revealed that Hel 13-5 con- tributed to negative line tension at the LE/LC phase boundary although there were few substantial interactions between Hel 13-5 and the lipid components. The $\Delta V-A$ isotherms showed hysteresis between the compression and 


\section{H. Nakahara and O. Shibata}

expansion cycles; this indicated the electrostatic attractions between the dissociated PA and negatively charged Hel 13-5. The compression-expansion isotherms of the mixture that contained only $2.5 \mathrm{~mol} \% \mathrm{Hel} 13-5$ revealed good reproducibility among the cycles and a large hysteresis loop. Consequently, the present study indicated the possibility of the production of pulmonary surfactants at low cost, which supports their potential application for treatment of a wide variety of respiratory diseases.

\section{ACKNOWLEDGEMENTS}

This work was supported by a Grant-in-Aid for Scientific Research 26350534 from the Japan Society for the Promotion of Science (JSPS). It was also supported by a Grant-inAid for Young Scientists (B) 25790020 from JSPS.

\section{REFERENCES}

1) Pérez-Gil, J.; Keough, K. M. W. Interfacial properties of surfactant proteins. Biochim. Biophys. Acta 1408, 203-217 (1998).

2) Veldhuizen, R.; Nag, K.; Orgeig, S.; Possmayer, F. The role of lipids in pulmonary surfactant. Biochim. Biophys. Acta 1408, 90-108(1998).

3) Krüger, P.; Baatz, J. E.; Dluhy, R. A.; Lösche, M. Effect of hydrophobic surfactant protein SP-C on binary phospholipid monolayers. Molecular machinery at the air/water interface. Biophys. Chem. 99, 209-228 (2002)

4) Yu, S.-H.; Possmayer, F. Lipid compositional analysis of pulmonary surfactant monolayers and monolayer-associated reservoirs. J. Lipid Res. 44, 621-629(2003).

5) Notter, R. H. Lung surfactants: Basic science and clinical applications. 149; Ed.; Marcel Dekker, Inc.: New York, Basel, pp 1-444(2000).

6) Batenburg, J. J.; Haagsman, H. P. The lipids of pulmonary surfactant: dynamics and interactions with proteins. Prog. Lipid Res. 37, 235-276 (1998).

7) Cochrane, C. G. Pulmonary surfactant in allergic inflammation: New insights into the molecular mechanisms of surfactant function. Am. J. Physiol. 288, L608-L609 (2005).

8) Pérez-Gil, J. Structure of pulmonary surfactant membranes and films: the role of proteins and lipid-protein interactions. Biochim. Biophys. Acta 1778, 16761695 (2008).

9) Revak, S. D.; Merritt, T. A.; Cochrane, C. G.; Heldt, G. P.; Alberts, M. S.; Anderson, D. W.; Kheiter, A. Efficacy of synthetic peptide-containing surfactant in the treatment of respiratory distress syndrome in preterm infant rhesus monkeys. Pediatr. Res. 39, 715-724
(1996).

10) Ma, J.; Koppenol, S.; Yu, H.; Zografi, G. Effects of a cationic and hydrophobic peptide, KL4, on model lung surfactant lipid monolayers. Biophys. J. 74, 18991907 (1998).

11) Wiswell, T. E.; Smith, R. M.; Katz, L. B.; Mastroianni, L.; Wong, D. Y.; Willms, D.; Heard, S.; Wilson, M.; Hite, R. D.; Anzueto, A.; Revak, S. D.; Cochrane, C. G. Bronchopulmonary segmental lavage with Surfaxin (KL (4) -surfactant) for acute respiratory distress syndrome. Am. J. Respir. Crit. Care Med. 160, 1188-1195 (1999).

12) Nakahara, H.; Lee, S.; Sugihara, G.; Chang, C.-H.; Shibata, O. Langmuir monolayer of artificial pulmonary surfactant mixtures with an amphiphilic peptide at the air/water interface: Comparison of new preparations with Surfacten (Surfactant TA). Langmuir 24, 33703379 (2008).

13) Nakahara, H.; Lee, S.; Krafft, M. P.; Shibata, O. Fluorocarbon-hybrid pulmonary surfactants for replacement therapy - a Langmuir monolayer study. Langmuir 26, 18256-18265(2010).

14) Kirkness, J. P.; Eastwood, P. R.; Szollosi, I.; Platt, P. R.; Wheatley, J. R.; Amis, T. C.; Hillman, D. R. Effect of surface tension of mucosal lining liquid on upper airway mechanics in anesthetized humans. J. Appl. Physiol. 95, 357-363(2003).

15) Kirkness, J. P.; Madronio, M.; Stavrinou, R.; Wheatley, J. R.; Amis, T. C. Relationship between surface tension of upper airway lining liquid and upper airway collapsibility during sleep in obstructive sleep apnea hypopnea syndrome. J. Appl. Physiol. 95, 1761-1766 (2003).

16) Pfister, R. H.; Soll, R. F. New Synthetic Surfactants: The Next Generation? Biol. Neonate 87, 338-344 (2005).

17) Pérez-Gil, J.; Casals, C.; Marsh, D. Interactions of hydrophobic lung surfactant proteins SP-B and SP-C with dipalmitoylphosphatidylcholine and dipalmitoylphosphatidylglycerol bilayers studied by electron spin resonance spectroscopy. Biochemistry 34, 39643971 (1995).

18) Tanaka, Y.; Takei, T.; Aiba, T.; Masuda, K.; Kiuchi, A.; Fujiwara, T. Development of synthetic lung surfactants. J. Lipid Res. 27, 475-485(1986).

19) Nakahara, H.; Shibata, O. Miscibility of egg yolk lecithin with palmitic acid and hexadecanol at the air-water interface. J. Oleo Sci. 62, 471-480 (2013).

20) Nakahara, H.; Lee, S.; Sugihara, G.; Shibata, O. Mode of interaction of hydrophobic amphiphilic a-helical peptide/dipalmitoylphosphatidylcholine with phosphatidylglycerol or palmitic acid at the air-water interface. Langmuir 22, 5792-5803 (2006).

21) Nakahara, H.; Nakamura, S.; Hiranita, T.; Kawasaki, H.; 


\section{Lipid substitute of lung surfactants for DPPC}

Lee, S.; Sugihara, G.; Shibata, O. Mode of interaction of amphiphilic $\alpha$-helical peptide with phosphatidylcholines at the air-water interface. Langmuir 22, 1182 1192 (2006).

22) Nakahara, H.; Lee, S.; Shibata, O. Pulmonary surfactant model systems catch the specific interaction of an amphiphilic peptide with anionic phospholipid. Biophys. J. 96, 1415-1429 (2009).

23) Kiyota, T.; Lee, S.; Sugihara, G. Design and synthesis of amphiphilic a-helical model peptides with systematically varied hydrophobic-hydrophilic balance and their interaction with lipid- and bio-membranes. Biochemistry 35, 13196-13204(1996).

24) Furuya, T.; Kiyota, T.; Lee, S.; Inoue, T.; Sugihara, G.; Logvinova, A.; Goldsmith, P.; Ellerby, H. M. Nanotubules formed by highly hydrophobic amphiphilic a-helical peptides and natural phospholipids. Biophys. J. 84, 1950-1959 (2003).

25) Lee, S.; Furuya, T.; Kiyota, T.; Takami, N.; Murata, K.; Niidome, Y.; Bredesen, D. E.; Ellerby, H. M.; Sugihara, G. De novo-designed peptide transforms Golgi-specific lipids into Golgi-like nanotubules. J. Biol. Chem. 276, 41224-41228(2001).

26) Nakahara, H.; Lee, S.; Shibata, O. Surface pressure induced structural transitions of an amphiphilic peptide in pulmonary surfactant systems by an in situ PM-IRRAS study. Biochim. Biophys. Acta 1828, 1205-1213 (2013).

27) Nakamura, Y.; Yukitake, K.; Nakahara, H.; Lee, S.; Shibata, O.; Lee, S. Improvement of pulmonary surfactant activity by introducing D-amino acids into highly hydrophobic amphiphilic $\alpha$-peptide Hel 13-5. Biochim. Biophys. Acta 1838, 2046-2052 (2014).

28) Yukitake, K.; Nakamura, Y.; Kawahara, M.; Nakahara, H.; Shibata, O.; Lee, S. Development of low cost pulmonary surfactants composed of a mixture of lipids or lipids-peptides using higher aliphatic alcohol or soy lecithin. Colloids Surf. B 66, 281-286(2008).

29) Hiranita, T.; Nakamura, S.; Kawachi, M.; Courrier, H. M.; Vandamme, T. F.; Krafft, M. P.; Shibata, O. Miscibility behavior of dipalmitoylphosphatidylcholine with a single-chain partially fluorinated amphiphile in Langmuir monolayers. J. Colloid Interf. Sci. 265, 83-92 (2003).

30) Nakamura, S.; Nakahara, H.; Krafft, M. P.; Shibata, O. Two-component Langmuir monolayers of single-chain partially fluorinated amphiphiles with dipalmitoylphosphatidylcholine (DPPC) . Langmuir 23, 12634-12644 (2007).

31) Nakahara, H.; Tsuji, M.; Sato, Y.; Krafft, M. P.; Shibata, O. Langmuir monolayer miscibility of single-chain partially fluorinated amphiphiles with tetradecanoic acid. J. Colloid Interf. Sci. 337, 201-210 (2009).

32) Nakahara, H.; Shibata, O.; Moroi, Y. Examination of surface adsorption of sodium chloride and sodium do- decyl sulfate by surface potential measurement at the air/solution interface. Langmuir 21, 9020-9022 (2005).

33) Nakahara, H.; Shibata, O.; Rusdi, M.; Moroi, Y. Examination of Surface Adsorption of Soluble Surfactants by Surface Potential Measurement at the Air/Solution Interface. J. Phys. Chem. C 112, 6398-6403(2008).

34) Nakahara, H.; Nakamura, S.; Kawasaki, H.; Shibata, O. Properties of two-component Langmuir monolayer of single chain perfluorinated carboxylic acids with dipalmitoylphosphatidylcholine(DPPC). Colloids Surf. B 41, 285-298 (2005).

35) Nakahara, H.; Lee, S.; Shibata, O. Specific interaction restrains structural transitions of an amphiphilic peptide in pulmonary surfactant model systems: An in situ PM-IRRAS investigation. Biochim. Biophys. Acta 1798, 1263-1271 (2010).

36) Nahmen, A. V.; Schenk, M.; Sieber, M.; Amrein, M. The structure of a model pulmonary surfactant as revealed by scanning force microscopy. Biophys. J. 72, 463469 (1997).

37) Lipp, M. M.; Lee, K. Y. C.; Takamoto, D. Y.; Zasadzinski, J. A.; Waring, A. J. Coexistence of buckled and flat monolayers. Phys. Rev. Lett. 81, 1650-1653(1998).

38) Nakahara, H.; Lee, S.; Shoyama, Y.; Shibata, O. The role of palmitic acid in pulmonary surfactant systems by Langmuir monolayer study: Lipid-peptide interactions. Soft Matter 7, 11351-11359 (2012).

39) Schürch, S.; Qanbar, R.; Bachofen, H.; Possmayer, F. The surface-associated surfactant reservoir in the alveolar lining. Biol. Neonate 67 Suppl 1, 61-76(1995).

40) Amrein, M.; von Nahmen, A.; Sieber, M. A scanning force- and fluorescence light microscopy study of the structure and function of a model pulmonary surfactant. Eur. Biophys. J. 26, 349-357 (1997).

41) Krol, S.; Ross, M.; Sieber, M.; Kunneke, S.; Galla, H.-J.; Janshoff, A. Formation of three-dimensional proteinlipid aggregates in monolayer films induced by surfactant protein B. Biophys. J. 79, 904-918(2000).

42) Takamoto, D. Y.; Lipp, M. M.; Von Nahmen, A.; Lee, K. Y. C.; Waring, A. J.; Zasadzinski, J. A. Interaction of lung surfactant proteins with anionic phospholipids. Biophys. J. 81, 153-169(2001).

43) Chen, K. B.; Chang, C. H.; Yang, Y. M.; Maa, J. R. On the interaction of dipalmitoyl phosphatidylcholine with normal long-chain alcohols in a mixed monolayer: a thermodynamic study. Colloids Surf. A 170, 199208(2000).

44) Lee, K. Y. C.; Gopal, A.; von Nahmen, A.; Zasadzinski, J. A.; Majewski, J.; Smith, G. S.; Howes, P. B.; Kjaer, K. Influence of palmitic acid and hexadecanol on the phase transition temperature and molecular packing of dipalmitoylphosphatidyl-choline monolayers at the air-water interface. J. Chem. Phys. 116, 774-783 
(2002).

45) Romão, R. I. S.; Gonçalves da Silva, A. M. Phase behaviour and morphology of binary mixtures of DPPC with stearonitrile, stearic acid, and octadecanol at the airwater interface. Chem. Phys. Lipids 131, 27-39 (2004).

46) Gopal, A.; Lee, K. Y. C. Headgroup percolation and collapse of condensed Langmuir monolayers. J. Phys. Chem. B 110, 22079-22087 (2006).

47) Weis, R. M.; McConnell, H. M. Two-dimensional chiral crystals of phospholipid. Nature 310, 47-49 (1984).

48) Weis, R. M.; McConnell, H. M. Cholesterol stabilizes the crystal-liquid interface in phospholipid monolay- ers. J. Phys. Chem. 89, 4453-4459 (1985).

49) Möhwald, H. Phospholipid and phospholipid-protein monolayers at the air/water interface. Annu. Rev. Phys. Chem. 41, 441-476(1990).

50) Thirumoorthy, K.; Nandi, N.; Vollhardt, D. Role of dipolar interaction in the mesoscopic domains of phospholipid monolayers: dipalmitoylphosphatidylcholine and dipalmitoylphosphatidylethanolamine. Langmuir 23, 6991-6996 (2007).

51) Banerjee, R.; Bellare, J. R. Scoring of surface parameters of physiological relevance to surfactant therapy in respiratory distress syndrome. J. Appl. Physiol. 90, 1447-1454(2001). 